\title{
Lipopolysaccharide-Induced Tumor Necrosis Factor- $\alpha$ and IL-10 Production by Lung Macrophages from Preterm and Term Neonates
}

\author{
MARTIN J. BLAHNIK, RANGASAMY RAMANATHAN, CELESTE R. RILEY, AND \\ PARVIZ MINOO \\ Divisions of Neonatology [M.J.B., R.R., P.M.] and Hematopathology [C.R.R.], Department of Pediatrics, \\ Women's and Children's Hospital, University of Southern California School of Medicine, Los Angeles, \\ California 90033, U.S.A.
}

\begin{abstract}
Lung injury in preterm neonates with respiratory failure has been attributed to persistent inflammation, which is likely to involve lung macrophages (LM). The study objective was to investigate LM during the first $8 \mathrm{~d}$ of life from preterm infants $(n$ $=19)$, using term infants $(n=11)$ with respiratory failure as control subjects. LM percentages from mixed-cell suspensions produced from tracheobronchial lavage were calculated. A postnatal increase in the mean LM concentration was demonstrated within the preterm group $(p=0.01)$, which was greater in comparison to that from the term group $(p<0.01)$. Regression analyses were significant for direct relationships between LM concentrations and ex vivo lipopolysaccharide-induced tumor necrosis factor- $\alpha$ and IL-10 production ( $r=0.93$ and $r=0.63$, respectively), establishing LM as the source of these cytokines. Comparative analyses demonstrated that the ability of preterm versus term LM to produce tumor necrosis factor- $\alpha$ was nearly identical; in contrast, a trend toward diminished levels of IL-10 expression in the preterm group was observed $(p=0.06)$. Thus,
\end{abstract}

\section{ABSTRACT}

although studies have shown that LM precursors (i.e. cord blood monocytes) produce less tumor necrosis factor- $\alpha$ in preterm versus term infants, the present data strongly suggest that this relationship does not hold postnatally with respect to terminally differentiated LM in sick neonates. Overall, the data are consistent with a pro- versus antiinflammatory imbalance that may bear functional significance on the pathogenesis of chronic lung disease. (Pediatr Res 50: 726-731, 2001)
LPS, lipopolysaccharide
LM, lung macrophage(s)
TBL, tracheobronchial lavage
TNF- $\alpha$, tumor necrosis factor- $\alpha$
CLD, chronic lung disease
DOL, day of life
RBC, red blood cell

Preterm infants who require mechanical ventilation are at increased risk for developing CLD, the pathogenesis of which is considered to be multifactorial $(1,2)$. Oxygen toxicity, barotrauma, acute and chronic infection, developmental arrest, and inflammation are critical etiologic factors. Particularly because the latter may be produced secondarily by most factors contributing to CLD evolution, an enhanced interest in determining its precise role has emerged. Data supporting the role of inflammation in CLD have largely come from studies that identified numerous markers of inflammation directly in TBL (3). The methodological concerns with this approach are well

Received January 3, 2001; accepted June 29, 2001.

Correspondence and reprint requests: Parviz Minoo, Ph.D., Division of Neonatology, Department of Pediatrics, Women's and Children's Hospital, 1801 E. Morengo Street, Room 1G1, Los Angeles, California 90033, U.S.A.; e-mail: minoo@hsc.usc.edu Supported by the Hastings Foundation (HL60231).

Preliminary data for this study were presented at the 2000 Annual Meeting of the Society for Pediatric Research in Boston, MA, U.S.A. recognized, e.g. inconsistent mixing of saline with the TBL effluent during endotracheal suctioning and the lack of a standardized denominator that could provide reliable determinations of in vivo cytokine levels $(4,5)$. Thus, sequential quantification of specific proinflammatory mediators in direct TBL studies has not been consistently related to bad outcomes. Furthermore, many studies using preterm cord blood monocytes (i.e. LM precursors) have shown multiple developmental deficiencies in the production of proinflammatory cytokines, e.g. interferon- $\gamma(6)$, granulocyte colony-stimulating factor (7), IL-8 (8), IL-6 $(9,10)$, and TNF- $\alpha(11,12)$. If preterm LM also possessed a relatively diminished competence for proinflammatory cytokine expression, the increased risk for CLD as ascribed to inflammation could be challenged.

TNF- $\alpha$ can be directly cytotoxic to parenchymal cells (13); it can also adversely affect the lungs by a mechanism involving the amplification of proinflammatory responses in autocrine and paracrine fashion $(3,13)$. Thus, regulatory mechanisms 
tightly controlling this multifaceted process are required to avoid inflammatory injury (or autoinjury). The antiinflammatory cytokine IL-10 has a role in ameliorating tissue damage owing to persistent inflammation $(14,15)$. In the lung this protective function likely requires adequate IL-10 production by LM. We reported a reduced level of IL-10 from the lungs of intubated preterm infants (16); however, the scope of this report did not involve an investigation of LM competence for cytokine expression.

To study the relative capacity for cytokine production by $\mathrm{LM}$ on a per-cell basis, and to avoid some of the shortcomings associated with direct TBL assays, we developed an ex vivo culture system that is amenable to standardization and quantification $(17,18)$. In vitro comparisons between preterm and term LM for pro- and antiinflammatory cytokine production are relevant to the pathogenesis of CLD, inasmuch as the magnitude of cell responsiveness to LPS can be interpreted as representing the relative intactness of activation pathways in vivo between the two groups of neonates with relatively different risks for CLD.

The ex vivo culture system was used in the current study in light of three hypotheses: 1) LM, as opposed to other cell types commonly recovered from TBL, are the main source of cytokine production after in vitro LPS stimulation. 2) If persistent inflammation is a key pathologic feature of CLD in preterm infants, then LM should be competent to produce proinflammatory cytokines, such as TNF- $\alpha$. 3) Expression of the antiinflammatory cytokine IL-10 may not be sufficient to downmodulate a number of mediators that are likely to contribute to autoinjury.

The major obstacle to the ex vivo investigation of LM cytokine production is the inability to obtain TBL-derived pure LM populations. Thus, we determined that a comparative analysis of preterm versus term LM potential for TNF- $\alpha$ and IL-10 expression in response to LPS required the normalization of cytokine levels, i.e. computing cytokine production for a single LM concentration (or cytokine quantification on a percell basis). The precondition for normalizing cytokine levels was the establishment of LM as the predominant source of TNF- $\alpha$ and IL-10 (the first hypothesis). Thereafter, data relevant to the second and third hypotheses could be obtained.

\section{METHODS}

Subjects. The study protocol was reviewed and accepted by the Institutional Review Boards at the University of Southern California Women's and Children's Hospital and Children's Hospital Los Angeles. Preterm ( $\leq 33$ wk) and term ( $\geq 37$ wk) neonates with respiratory failure in the first $24 \mathrm{~h}$ were eligible for recruitment during the first $8 \mathrm{~d}$ of life. This included the use of TBL as obtained by routine neonatal intensive care unit practices. Collection of samples occurred from January 1999 to July 2000. Exclusion criteria included major dysmorphology, pulmonary hemorrhage (or $>5 \%$ RBCs on cytospin), and corticosteroid therapy.

Study protocol. Investigators were required to restrict specimen collections to times when routine clearance of the endotracheal tube was necessary as determined by the neonatal nurse or respiratory therapist. Typically, this occurred every 2-12 h, depending on the amount of secretions or changes in clinical status. The TBL procedure was routine: instillation of $1-2 \mathrm{~mL}$ of normal saline solution through a $5 \mathrm{~F}$ or $8 \mathrm{~F}$ suction catheter introduced via a slide valve in the endotracheal tube connector. Saturation by continuous pulse oximetry was monitored in all infants during suctioning, and the fraction of inspired oxygen was increased as indicated to maintain oxygen saturation in the desired range.

TBL fluids were processed within $1 \mathrm{~h}$ of collection. Processing included initial centrifugation at $1200 \mathrm{rpm}$ for $5 \mathrm{~min}$, after which the pellet was resuspended in complete medium, consisting of RPMI $+10 \%$ FCS supplemented with $2 \mathrm{mM} \mathrm{L-}$ glutamine, $100 \mathrm{U} / \mathrm{mL}$ penicillin, and $100 \mu \mathrm{g} / \mathrm{mL}$ streptomycin. The volume of complete medium used to resuspend the pellet was an underestimation so as to yield a cell count not $<5 \times$ $10^{5}$ cells $/ \mathrm{mL}$; but if $>1 \times 10^{6}$ cells $/ \mathrm{mL}$, additional complete medium was added to the cell suspension and the cell count was determined again using the hemocytometer. Aliquots of 50,000 cells (per slide) from the final cell suspension were used for cytopreps, which were prepared in a Shandon 3 Cytospin (Thermo Shandon, Inc., Pittsburgh, PA, U.S.A.) at $500 \mathrm{rpm}$ for $5 \mathrm{~min}$. The slides were air-dried and then stained with WrightGiemsa stain (Fig. 1), after which cell differentials were manually counted microscopically at $\times 40$ based on cytologic

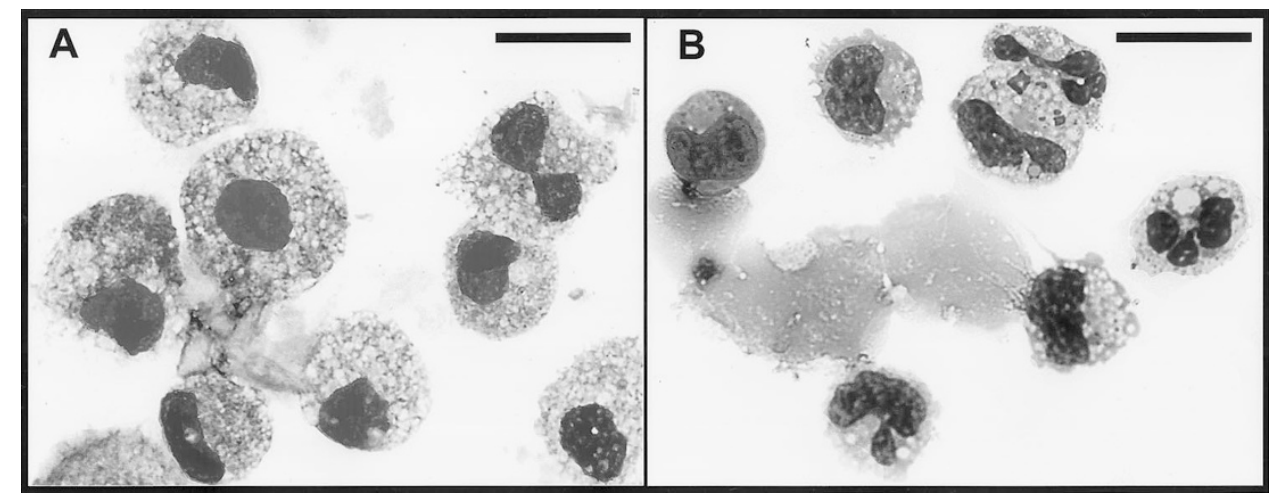

Figure 1. Representative morphologic distinctions between LM obtained from preterm $(A)$ and term $(B)$ infants. Large, vacuolated LM predominated in DOL 4-8 TBL from preterm infants, an appearance consistent with an activated state. The example of cell types from a term infant shows a mixture that includes LM and neutrophils in the presence of mucus. (Wright-Giemsa stain; $\times 100$ magnification; scale bar represents $10 \mu \mathrm{m}$ ). 
morphology. The accuracy of manual counting was challenged by submitting 13 TBL cell suspensions to concurrent flow cytometric immunophenotyping (see below). Cell differentials allowed the calculation of cell-specific concentrations. Mixedcell suspensions adjusted to $5 \times 10^{5}$ cells $/ \mathrm{mL}$ were placed in 24-h culture as controls without LPS and with LPS $(10 \mathrm{ng} / \mathrm{mL}$; from Escherichia coli, Sigma Chemical Co., St. Louis, MO, U.S.A.), and $500-$ to $800-\mu \mathrm{L}$ suspensions were incubated at $37^{\circ} \mathrm{C}$ with $5.6 \% \mathrm{CO}_{2}$ and $21 \% \mathrm{O}_{2}$.

After $24 \mathrm{~h}$ the cell suspensions were centrifuged at $1200 \mathrm{rpm}$ for $5 \mathrm{~min}$, and the supernatants were frozen at $-80^{\circ} \mathrm{C}$ for batched ELISAs to measure TNF- $\alpha$ and IL-10 within $45 \mathrm{~d}$. The ELISA kits (R\&D Systems, Inc., Minneapolis, MN, U.S.A.) were sensitive to concentrations of TNF- $\alpha$ at $15 \mathrm{pg} / \mathrm{mL}$ and IL-10 at $7.5 \mathrm{pg} / \mathrm{mL}$.

Flow cytometry. TBL from a subset $(n=13)$ of the study population were used for flow cytometric analysis. TBL samples were processed as described above, except that each specimen was filtered through a 50- $\mu \mathrm{m}$ mesh before the initial centrifugation step. The procedure for labeling cells has been described previously $(19,20)$. Only minor modifications in cell number and lysing were used. In summary, unlysed $2.5 \times 10^{5}$ cell aliquots were incubated with titered MAb for $15 \mathrm{~min}$, then washed and analyzed without paraformaldehyde fixation. The antibodies tested included CD45 (Beckman Coulter, Fullerton, CA, U.S.A.), CD33 (Beckman Coulter), CD71 (Immunotech, Marseille, France), and CD11c (Immunotech). The antibodies were used in the following three-color, multiparameter, twotube setup: CD71FITC/CD33RD/CD45Cy5 (tube 1) and CD11cFITC/CD33RD/CD45Cy5 (tube 2). The utility of tube 1 has been previously demonstrated for enumerating cellular subsets of lymphocytes (bright CD45 and low side scatter), monocytes (bright CD45 and moderate side scatter), and granulocytes (moderate CD45 and moderate to bright side scatter) $(19,20)$. CD45-negative cellular subsets, such as epithelial cells, are easily delineated from the hematopoietic cells in both tubes 1 and 2 . In addition, tube 1 serves to illustrate the activation level of each of these subgroups via the expression level of CD71 (transferrin), which is up-regulated in activated and proliferating cells $(19,20)$. Tube 2 allows further confirmation of the enumeration of mononuclear phagocytes, which are CD11c-positive.

Study definitions. Three definitions were used in this study:

1. Two clinical periods were defined for statistical comparison: an acute phase of lung injury during DOL $1-3$, and an exudative phase of lung disease during DOL 4-8 (Fig. 2).

2. If TBL fluids were obtained from a subject during both time periods, a single data point from each of the two periods was recorded for data analyses (Figs. 2 and 3). Also, if sampling occurred more than once during a single period, an average data point was generated to provide a single data point representing that period (Figs. 2-4). As a result, excepting excluded TBL samples because of $>5 \%$ RBCs on cytospin, the total number of analyzed samples was 48 ; the total number of times an individual neonate was sampled ranged from one to four.

3. A requirement for $\geq 7.5 \times 10^{4} \mathrm{LM} / \mathrm{mL}$, which is $\geq 15 \%$ of the mixed-cell suspensions (i.e. processed TBL fluids ad-
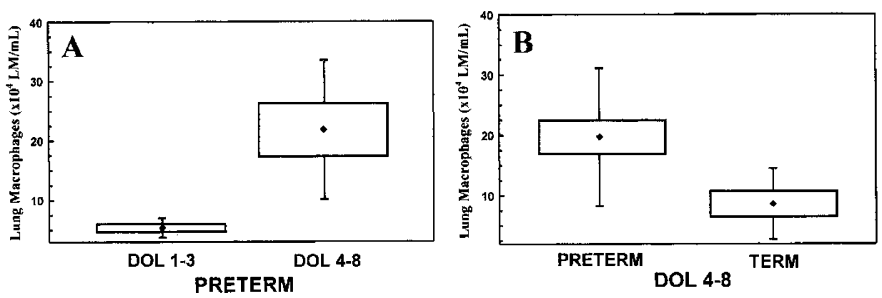

Figure 2. Postnatal changes in mean LM concentrations within the preterm group $(A)$; and DOL $4-8$ preterm versus term mean LM concentrations $(B)$. Box-whisker plots depict ranges, $95 \%$ confidence intervals (boxes), and means (dots). $A$, there was a significant increase in the mean LM concentration after the initial sampling period in this preterm subgroup $(n=7 ; p=0.01)$. $B$, a comparison of DOL 4-8 LM numbers revealed a significantly greater mean in the preterm $(n=17)$ versus term $(n=8)$ groups $(p=0.005)$.
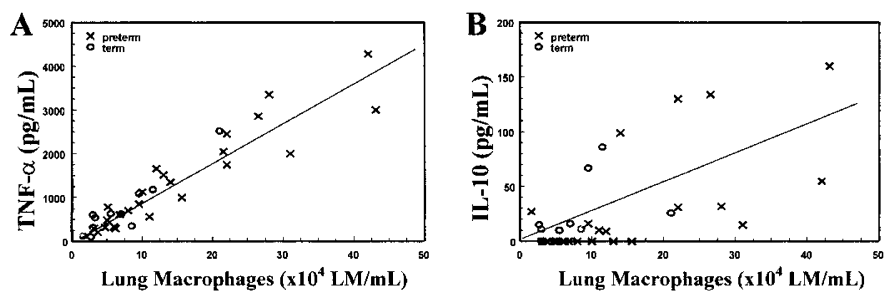

Figure 3. Regression analyses for TNF- $\alpha(A)$ and IL-10 (B) LPS-stimulated protein levels versus absolute numbers of LM. For TNF- $\alpha, n=35$ (preterm + term), $r=0.93, p<0.0001$; for IL-10, $n=34$ (preterm + term), $r=0.63$, $p<0.0001$. One data point per neonate per period (DOL $1-3$ or DOL $4-8$ or both) was accepted. Regression lines represent the composite of preterm and term data points.

justed to $5.0 \times 10^{5}$ cells $/ \mathrm{mL}$ ), was applied to the TNF- $\alpha$ and IL-10 normalization analysis (Fig. 4). Only DOL 4-8 samples met this requirement. TNF- $\alpha$ and IL-10 levels were normalized to values that would be produced if all cultures contained 1.5 $\times 10^{5} \mathrm{LM} / \mathrm{mL}$.

Statistical analyses. Analyses of data were completed using the computer program GB-Stat v7.0 (Dynamic Microsoft Systems, Inc., Silver Spring, MD, U.S.A.). Intra- and intergroup differences in mean LM concentrations at specific postnatal periods were analyzed by $t$ tests, using paired groups and separate variances, respectively. Student's $t$ tests were also used to compare mean cytokine protein levels within groups (control versus LPS-induced, paired groups) and between groups (LPS-induced, pooled variances). To compare flow
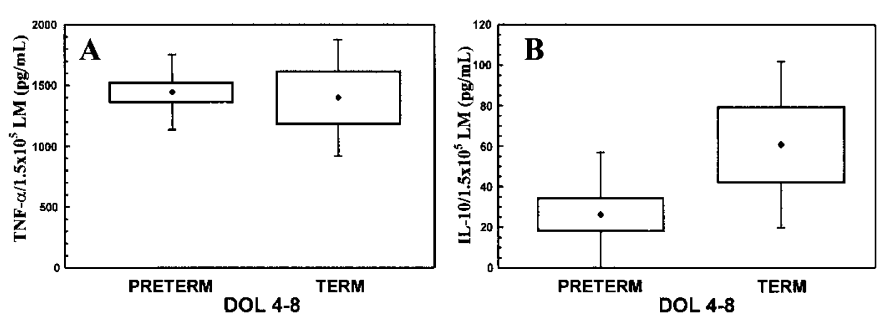

Figure 4. Preterm versus term assessment of normalized TNF- $\alpha(A)$ and IL-10 $(B)$ production. Box-whisker plots consist of ranges, 95\% confidence intervals (boxes), and means (dots). LM concentrations of $\geq 7.5 \times 10^{4} \mathrm{LM} / \mathrm{mL}$ were only found in TBL obtained during DOL $4-8$. This minimum concentration was a criterion for the current analysis (see "Methods"). $A$, preterm ( $n$ $=16)$ versus term $(n=5) \mathrm{TNF}-\alpha$ mean levels are very similar. $B$, in contrast, the magnitude of IL-10 expression revealed a trend in the preterm group $(n=$ 16) toward lower levels relative to the term $(n=5 ; p=0.06)$. 
cytometric versus manual differential determinations of relative percentages of four cell types in TBL, a $\chi^{2}$ analysis was used. A linear regression analysis was undertaken to determine correlation coefficients and statistical significance of cytokine levels versus LM concentrations. Where appropriate, $F$ tests were used to determine the homogeneity of variances, accepting $p<0.05$ as significant.

\section{RESULTS}

Study population profile. Characteristics of the subjects recruited for this study are provided in Table 1. Respiratory failure in the preterm group was secondary to respiratory distress syndrome or extreme prematurity; and in the term group it was secondary to meconium aspiration syndrome $(n=$ $8)$, idiopathic pulmonary hypertension $(n=1)$, congenital pneumonia $(n=1)$, and congenital diaphragmatic hernia $(n=$ 1). All cases of postnatal corticosteroid therapy in the preterm group were initiated after the TBL sampling period, i.e. treatment with dexamethasone was administered after DOL 8. In the term group, two patients receiving a single dose of dexamethasone for hypotension during the first $24 \mathrm{~h}$ of life were included.

Preterm and term LM morphology. Microscopically, differences in morphology between preterm and term LM are demonstrated in Figure 1. Preterm LM appear larger, have a lower nuclear-to-cytoplasmic ratio, and contain a greater number of large pale vacuoles suggesting a high degree of phagocytosis. This morphology is consistent with in vivo exposure to activation stimuli; however, differences in the degree of activation between preterm and term LM cannot be readily determined microscopically. Not shown here are preterm and term cytopreps that contain other cell types, such as occasional RBCs and lymphocytes $(<5 \%)$; overall, the majority of cytopreps were observed to have consistently high percentages of neutrophils and epithelial cells. The latter were often noted to be ciliated columnar cells during the early sampling period, whereas DOL $4-8$ epithelial cells tended to be more cuboidal or squamous.

Flow cytometric analysis. To determine the concordance between analytical methods, the relative percentages of four cell types (mononuclear phagocytes, epithelial cells, neutrophils, and lymphocytes) as obtained by morphologic evaluation of Wright-Giemsa stained cytopreps (400 cells per slide counted) versus flow cytometric analysis (see "Methods") were compared for 13 neonates. A $\chi^{2}$ analysis was performed for the mononuclear fraction alone as well as for the four cell subsets combined. The differences between methods were not significant.

Postnatal changes in the mean number of LM. Mean LM concentrations between DOL 1-3 and DOL 4-8 were compared (Fig. $2 A$ ). Of the 19 preterm neonates in this study, seven (gestational age, $27 \pm 3 \mathrm{wk}$; birth weight, $1013 \pm 429 \mathrm{~g}$ ) were sampled during both postnatal phases of lung injury (DOL 1-3 and DOL $4-8)$. The data demonstrate a postnatal increase in the number of $\mathrm{LM}\left(5.4 \times 10^{4} \pm 31 \%\right.$ versus $2.2 \times 10^{5} \pm 54 \%$ $\mathrm{LM} / \mathrm{mL}$, respectively; $p=0.01$ ). The remaining preterm infants recruited into this study were either extubated during DOL $1-3(n=2)$, or sampled only during DOL $4-8(n=10)$. The DOL $4-8$ mean LM concentration in the preterm $(n=17)$ versus term $(n=8)$ groups was significantly different (Fig. 2B; $2.0 \times 10^{5} \pm 59 \%$ versus $8.6 \times 10^{4} \pm 65 \% \mathrm{LM} / \mathrm{mL}$, respectively; $p=0.005$ ). Excluded from this analysis because of extubation during DOL 1-3 were two preterm (gestational age and birth weight, $33 \mathrm{wk}$ and $1915 \mathrm{~g}$, and $30 \mathrm{wk}$ and $1505 \mathrm{~g}$ ) and three term infants.

$T N F-\alpha$ and IL-10 production after ex vivo LPS stimulation. LPS $(10 \mathrm{ng} / \mathrm{mL})$ stimulated an increase in TNF- $\alpha$ detection levels in the preterm group $(1270 \pm 1167$ versus $52 \pm 63$ $\mathrm{pg} / \mathrm{mL} ; p=0.001, n=19)$ and in the term group $(775 \pm 710$ versus $24 \pm 34 \mathrm{pg} / \mathrm{mL} ; p=0.004, n=10)$. Similarly, LPS stimulation caused an increase in detectable IL-10 from the preterm group $(31.2 \pm 48$ versus $0.9 \pm 2.9 \mathrm{pg} / \mathrm{mL} ; p=0.017$, $n=16$ ). Unstimulated term controls did not produce IL-10 above the threshold of the ELISA, whereas exposure to LPS resulted in increased IL-10 production $(36.6 \pm 32 \mathrm{pg} / \mathrm{mL}, n=$ 6). ELISAs were not performed on all samples having $<7.5 \times$ $10^{4} \mathrm{LM} / \mathrm{mL}$, as the normalization analysis required $\geq 7.5 \times$ $10^{4} \mathrm{LM} / \mathrm{mL}$ (Fig. 4).

TNF- $\alpha$ and IL-10 production: relationship of cytokine secretion level to cell type. In Figure 3 a simple linear regression model was used to examine the relationship between the absolute LM number and the magnitude of cytokine production. Significant direct relationships are shown between the number of LM in TBL cell suspensions and the magnitude of TNF- $\alpha$ and IL-10 production in response to LPS $(n=35, r=$ 0.93, $p<0.0001$ and $n=34, r=0.63, p<0.0001$,

Table 1. Study population profile

\begin{tabular}{lcc}
\hline \multicolumn{1}{c}{ Characteristic } & Preterm $(n=19)$ & Term $(n=11)$ \\
\hline Gestational age (wk) & $28 \pm 3.2(24-33)$ & $>37$ \\
Birth weight (g) & $1090 \pm 461(480-1915)$ & $3573 \pm 445(2586-4250)$ \\
Antenatal steroids & $10(53)$ & $0(0)$ \\
Postnatal steroids & $7(37)^{*}$ & $2(18) \dagger$ \\
Surfactant therapy & $16(84)$ & $4(36)$ \\
Mechanical ventilation (d) & $29 \pm 34(2-116) \dagger$ & $9 \pm 7(3-23)$ \\
No. days on oxygen & $71 \pm 63(7-252) \dagger$ & $15 \pm 9(4-31)$ \\
No. hospital days & $84 \pm 59(18-252) \dagger$ & $22 \pm 16(10-58)$ \\
\hline
\end{tabular}

Values are shown as mean \pm SD (range) or number (\%).

* All seven cases of dexamethasone therapy were initiated after the study period.

$\dagger p<0.01 v s$. term group.

t Two cases consisted of a single dose of dexamethasone in the first $24 \mathrm{~h}$ of life for hypotension. 
respectively). These data indicate that $\mathrm{LM}$ were the major cell type involved in expression of TNF- $\alpha$ and IL-10. Positive linear relationships between other cell types - notably, neutrophils and epithelial cells-were not significant (data not shown). Also, when group regression lines were compared (i.e. preterm versus term for TNF- $\alpha$ and IL-10), no significant differences were found.

The capacity of preterm and term LM to produce TNF- $\alpha$ and $\mathbf{I L}$-10. As stated in the "Methods", a minimum of $7.5 \times$ $10^{4} \mathrm{LM} / \mathrm{mL}$ was required for normalization of cytokine levels to avoid amplifying small cytokine concentrations potentially produced by large numbers of non-LM cell types - namely, neutrophils or epithelial cells. Consequently, only a subset of samples obtained during DOL 4-8 was analyzed; none of the samples obtained during DOL $1-3$ had $\geq 7.5 \times 10^{4} \mathrm{LM} / \mathrm{mL}$. During DOL $4-8,17$ of 19 preterm and eight of 11 term infants were still intubated; of these, 16 of 17 preterm and five of eight term subjects had $\geq 7.5 \times 10^{4} \mathrm{LM} / \mathrm{mL}$. As shown in Figure 4 , the preterm and term groups did not differ with respect to the capacity of LM to produce TNF- $\alpha(1444 \pm 308$ versus $1398 \pm 479 \mathrm{pg} / \mathrm{mL}$, respectively; NS); but a trend toward less IL-10 in the preterm group was noted (26 \pm 31 versus $61 \pm 41 \mathrm{pg} / \mathrm{mL} ; p=0.06$ ).

\section{DISCUSSION}

In this study, in vitro data accounting for cytokine production by LPS-stimulated TBL cell samples demonstrate that positive direct relationships exist between cytokine quantity and LM numbers (Fig. 3). We used an ex vivo culture system to determine the potential of LM to produce TNF- $\alpha$ and IL-10. This approach resembles published assays for cytokine production by cord blood monocytes (LM precursors). However, contrary to cord blood studies that found TNF- $\alpha$ to be developmentally regulated $(11,12,21,22)$, our data show that LM activation induced a nearly identical magnitude of TNF- $\alpha$ in the preterm versus term groups (Fig. $4 A$ ). In contrast, a trend toward reduced IL-10 production was observed in preterm LM when compared with term LM (Fig. 4B).

These findings can be interpreted in light of the three hypotheses considered central to this study. That LM are the likely source of cytokines is supported by the regression analyses (Fig. 3). Samples having low numbers of LM produced less TNF- $\alpha$ and IL-10; therefore, because such samples had high numbers of neutrophils or epithelial cells, it appears that these cell types respond to LPS in vitro with little cytokine production. Similar relationships may also exist in vivo whenever mechanically ventilated lungs are subjected to activation stimuli. However, in vitro culture conditions could preferentially favor LM survival, thus optimizing cytokine production per cell. Also, other parenchymal cells generally not recovered in TBL could be an in vivo source of cytokines.

TBL samples from preterm infants during DOL 4-8 produced the highest absolute cytokine levels in response to LPS, consistent with this sampling period having the highest number of LM (Fig. 2). Presumably, an increasing number of TBLderived LM reflects monocytes entering the pulmonary spaces and responding to tissue-specific differentiation factors. Nor- mal LM accumulation is known to take place during the first postnatal week $(23,24)$, but it can be accelerated by illness and mechanical ventilation (24). Even though the greater LM numbers in the preterm group could be an indication of illness severity, consistent with a greater length of mechanical ventilation and $\mathrm{O}_{2}$ requirements (Table 1), and the nonquiescent morphologic appearance of preterm LM (Fig. 1), the study design did not investigate this question directly. Furthermore, comparisons with the control group, i.e. term infants having a different disease whose pathogenesis may follow a different timeline, should be made with caution.

The second and third hypotheses propose that a pro- versus antiinflammatory imbalance might persist in a pulmonary microenvironment in which neonates receiving mechanical ventilation are subjected to multiple stimuli. We previously showed that TBL from preterm and term infants contained comparable quantities of TNF- $\alpha$, but reduced preterm IL-10, suggesting an imbalance between the pro- and antiinflammatory capabilities in immature lungs (16). A variety of other proinflammatory markers has been identified in TBL from our group (16-18) and others (25-28) (e.g. IL-1 $\beta$, IL-6, IL-8, C5a, leukotriene $\mathrm{B}_{4}$ ). However, these data do not show relative competence for cytokine synthesis on a per-cell basis between the high CLD-risk (preterm) and low CLD-risk (term) groups. On the contrary, comparisons of these groups in cord blood monocyte studies have demonstrated multiple developmental deficiencies in proinflammatory cytokine production in the high CLD-risk infants (6-12).

We developed the ex vivo culture system to investigate relative competence for cytokine production from infants receiving mechanical ventilation $(17,18)$. From the data in this report, it appears that cord blood differences in LPS-induced TNF- $\alpha$ synthesis between preterm and term infants may not persist postnatally in more terminally differentiated LM (Fig. 4), suggesting differentiation and activation pathways in cells of the mononuclear phagocytic lineage are functional in sick preterm infants. This example of postnatal adaptation may apply to other proinflammatory cytokines produced in lesser amounts in preterm compared with term mononuclear cells after LPS stimulation (6-12). However, this report is the first to describe cytokine production by human neonatal LM on a per-cell basis.

Given that the ex vivo culture system appreciably reflects in vivo LM activity, the data show a trend consistent with preterm infants having an IL-10 deficiency (Fig. $4 B, p=0.06$ ). Interestingly, Figure $3 B$ suggests two populations of preterm infants: one a more robust IL-10 producer than the other. Additional analysis is needed to determine whether preterm subpopulations exist, in which conceivably a low capacity for IL-10 expression is predictive of CLD and, conversely, a high capacity protective. If abnormal cell signaling occurs in LM of some infants, in effect arresting IL-10 production, a predisposition to CLD could result owing to the inability to downmodulate potentially deleterious proinflammatory cytokines.

The ex vivo pro- versus antiinflammatory cytokine profile observed in the preterm group could be either a manifestation of disparate maturation among the cytokines or aberrant cellular responses to ex utero stimuli. What factors are involved in 
the developmental regulation of cytokine gene expression and signaling remain largely unknown. And because the artificial conditions necessary to sustain life outside the uterus, particularly for extremely premature infants, are unavoidably invasive, it is perhaps not surprising that immature tissues such as the lungs respond adversely. A proinflammatory bias by LM has implications regarding the mechanism by which pulmonary inflammation can be injurious. This bias can promote the transendothelial recruitment and chemoattraction of neutrophils and mononuclear phagocytes, and the differentiation and activation of these and resident cell types; it can promote fluid retention that in turn leads to more barotrauma and oxygen toxicity. Finally, an uncontrolled proinflammatory milieu could adversely affect cellular events guiding the development of immature lungs, particularly the process of alveolarization. On the other hand, increasing evidence suggests that lung inflammation and ultimately fibrosis are separate processes regulated in complex ways. A targeted disruption of the integrin $\alpha \mathrm{v} \beta 6$ failed to activate transforming growth factor- $\beta$, causing exaggerated inflammation after bleomycin challenge, and yet the lungs were protected from fibrosis (29). IL-10 knockout mice developed a greater inflammatory response than wild-type mice when instilled with silica, but fibrosis was less (30).

Although we have provided data regarding the relative competence for cytokine production on a per-cell basis between different CLD-risk groups, the total number of LM producing the in vivo cytokine pool was not measured. The in vitro findings are also limited in that TNF- $\alpha$ and IL-10 are only two of the many cytokines known to be expressed in vivo. Therefore, to be able to create novel therapies aimed at preventing persistent inflammation, pathologic lung injury, and ultimately CLD, a greater understanding of the pro- versus antiinflammatory imbalance that may be exaggerated in mechanically ventilated premature lungs is needed.

\section{REFERENCES}

1. Bonikos DS, Bensch KG 1986 Pathogenesis of bronchopulmonary dysplasia. In: Merritt TA, Northway Jr WH, Boynton BR (eds) Bronchopulmonary Dysplasia. Blackwell Scientific, Boston, pp 33-58

2. Rojas MA, Gonzalez A, Bancalari E, Claure N, Poole C, Silva-Neto G 1995 Changing trends in the epidemiology and pathogenesis of neonatal chronic lung disease. J Pediatr 126:605-610

3. Ozdemir A, Brown MA, Morgan WJ 1997 Markers and mediators of inflammation in neonatal lung disease. Pediatr Pulmonol 23:292-306

4. Darlow BA, Sluis KB, Inder TE, Winterbourn CC 1997 Endotracheal suctioning of the neonate: comparison of two methods as a source of mucus material for research. Pediatr Pulmonol 23:217-221

5. NHLBI Workshop Summary 1993 Assessment of lung function and dysfunction in studies of infants and children. Am Rev Respir Dis 148:1105-1108

6. Saito S, Kato Y, Maruyama M, Ichijo M 1992 A study of interferon-gamma and interleukin-2 production in premature neonates and neonates with intrauterine growth retardation. Am J Reprod Immunol 27:63-68
7. Schibler KR, Liechty KW, White WL, Christensen RD 1993 Production of granulocyte colony-stimulating factor in vitro by monocytes from preterm and term neonates. Blood 82:2269-2284

8. Schibler KR, Trautman MS, Liechty KW, White WL, Rothstein G, Christensen RD 1993 Diminished transcription of interleukin-8 by monocytes from preterm neonates. J Leukoc Biol 53:399-403

9. Schibler KR, Liechty KW, White WL, Rothstein G, Christensen RD 1992 Defective production of interleukin- 6 by monocytes: a possible mechanism underlying several host defense deficiencies of neonates. Pediatr Res 31:18-21

10. Yachie A, Takano N, Ohta K, Uehara T, Fujita S, Miyawaki T, Taniguchi N 1992 Defective production of interleukin-6 in very small premature infants in response to bacterial pathogens. Infect Immun 60:749-753

11. Weatherstone KB, Rich EA 1989 Tumor necrosis factor/cachectin and interleukin-1 secretion by cord blood monocytes from premature and term neonates. Pediatr Res 25:342-346

12. Kaufman D, Kilpatrick L, Hudson RG, Campbell DE, Kaufman A, Douglas SD, Harris MC 1999 Decreased superoxide production, degranulation, tumor necrosis factor-alpha secretion, and CD11b/CD18 receptor expression by adherent monocytes from preterm infants. Clin Diagn Lab Immunol 6:525-529

13. Zhang M, Tracey KJ 1998 Tumor necrosis factor. In: Thomson AW (ed) The Cytokine Handbook. Academic Press, San Diego, pp 517-548

14. Rennick DM, Fort MM, Davidson NJ 1997 Studies with IL-10 -/- mice: an overview. J Leukoc Biol 61:389-396

15. de Waal Malefyt R, Moore KW 1998 Interleukin-10. In: Thomson AW (ed) The Cytokine Handbook. Academic Press, San Diego, pp 333-364

16. Jones CA, Cayabyab RG, Kwong KYC, Stotts C, Wong B, Hamdan H, Minoo P, deLemos RA 1996 Undetectable interleukin (IL)-10 and persistentIL-8 expression early in hyaline membrane disease: a possible developmental basis for the predisposition to chronic lung inflammation in preterm newborns. Pediatr Res 39:966-975

17. Kwong KY, Jones CA, Cayabyab R, LeCart C, Stotts CL, Randhawa I, Ramanathan R, Khuu N, Minoo P, deLemos RA 1998 Differential regulation of IL-8 by IL- $1 \beta$ and $\mathrm{TNF} \alpha$ in hyaline membrane disease. J Clin Immunol 18:71-80

18. Kwong KYC, Jones CA, Cayabyab R, LeCart C, Khuu N, Randhawa I, Hanley JM, Ramanathan R, deLemos RA, Minoo P 1998 The effects of IL-10 on proinflammatory cytokine expression (IL-1 $\beta$ and IL-8) in hyaline membrane disease (HMD). Clin Immunol Immunopathol 88:105-113

19. Borowitz MJ, Guenther KL, Shultz KE, Steizer GT 1993 Immunophenotyping of acute leukemia by flow cytometric analysis. Am J Clin Pathol 100:534-541

20. Jennings CD, Foon KA 1997 Recent advances in flow cytometry: application to the diagnosis of hematologic malignancy. Blood 90:2863-2892

21. Chheda S, Palkowetz KH, Garofalo R, Rassin DK, Goldman AS 1996 Decreased interleukin-10 production by neonatal monocytes and $\mathrm{T}$ cells: relationship to decreased production and expression of tumor necrosis factor- $\alpha$ and its receptors. Pediatr Res 40:475-483

22. Serushago B, Issekutz AC, Lee SHS, Rajaraman K, Bortolussi R 1996 Deficient tumor necrosis factor secretion by cord blood mononuclear cells upon in vitro stimulation with Listeria monocytogenes. J Interferon Cytokine Res 16:381-387

23. Bellanti JA, Nerurkar LS, Zeligs BJ 1979 Host defenses in the fetus and neonate: studies of the alveolar macrophage during maturation. Pediatrics 64(suppl):726-739

24. Alenghat E, Esterly JR 1984 Alveolar macrophages in perinatal infants. Pediatrics 74:221-223

25. Bagchi A, Viscardi RM, Taciak V, Ensor JE, McCrea KA, Hasday JD 1994 Increased activity of interleukin- 6 but not tumor necrosis factor- $\alpha$ in lung lavage of premature infants is associated with the development of bronchopulmonary dysplasia. Pediatr Res 36:244-252

26. Groneck P, Gotze-Speer B, Oppermann M, Eiffert H, Speer CP 1994 Association of pulmonary inflammation and increased microvascular permeability during the development of bronchopulmonary dysplasia: a sequential analysis of the inflammatory mediators in respiratory fluids of high-risk preterm neonates. Pediatrics 93:712-718

27. Kotecha S, Wilson L, Wangoo A, Silverman M, Shaw RJ 1996 Increase in interleukin (IL)- $1 \beta$ and IL-6 in bronchoalveolar lavage fluid obtained from infants with chronic lung disease of prematurity. Pediatr Res 40:250-256

28. Watterberg KL, Demers LM, Scott SM, Murphy S 1996 Chorioamnionitis and early lung inflammation in infants in whom bronchopulmonary dysplasia develops. Pediatrics 97:210-215

29. Huaux F, Louahed J, Hudspith B, Meredith C, Delos M, Renauld JC, Lison D 1998 Role of interleukin-10 in the lung response to silica in mice. Am J Respir Cell Mol Biol 18:51-59

30. Munger JS, Huang X, Kawakatsu H, Griffiths MJD, Dalton SL, Wu J, Pittet JF, Kaminski N, Garat C, Matthay MA, Rifkin DB, Sheppard D 1999 The integrin $\alpha v \beta 6$ binds and activates latent TGF $\beta 1$ : a mechanism for regulating pulmonary inflammation and fibrosis. Cell 96:319-328 